\title{
Associations of Language-based Bedtime Routines with Early Cognitive Skills and Academic Achievement: a Follow-Up from Kindergarten to Middle School
}

\section{Language-based bedtime routines and academic achievement}

\author{
Hugo Câmara-Costa ${ }^{1,2 *}$, Salomé Pulgar ${ }^{3}$, Françoise Cusin ${ }^{3}$, \\ Florence Labrell ${ }^{4,5}$ and Georges Dellatolas ${ }^{2}$
}

1 Sorbonne Université, CNRS, INSERM, Laboratoire d'Imagerie Biomédicale, LIB, F-75006, Paris, France

2 Clinical Research Group on Cognitive Disability and Rehabilitation (HanCRe), Sorbonne Université, Paris, France

3 National Department of Education, Academic Inspectorate, Mâcon, France

4 Université Paris-Saclay, UVSQ, Inserm, CESP, 94807, Villejuif, France

5 National Institute for Training and Research on Special Needs Education (INSHEA), Research Group on Disability, Accessibility and Special Education Needs (Grhapes) EA 7287, Suresnes, France

*Corresponding author: Hugo Câmara-Costa, Laboratoire d'Imagerie Biomédicale (LIB), Laboratoire du Service de Rééducation de l'Hôpital Pitié-Salpêtrière (1er étage), 75013 Paris, France. hugocamaracosta@ gmail.com. Tel.: +33 (0) 646534466.

Running title: Bedtime routines and academic achievement 


\section{Acknowledgments}

The present research was supported in part by Fédération des Euvres Laïques of the Urban Community of Creusot-Montceau, the French Ministry of Health, France Foundation (Fondation de France), INSERM (Institut National de la Santé et de la Recherche Médicale) and MGEN (Mutuelle Générale de l'Éducation Nationale - Projet Maternelle). We are very thankful to the members of the research team, the school doctors and nurses of the National Department of Education, and the pediatricians, teachers and children in the Le Creusot Montceau-les-Mines for their participation in the study.

\section{Data availability statement}

The data that support the findings of this study are available on request from the corresponding author. The data are not publicly available due to privacy or ethical restrictions.

\section{Conflict of interest}

None 
RUNNING HEAD: Bedtime routines and academic achievement

\begin{abstract}
Objective: This study aimed to investigate the extent to which language-based bedtime routines (LBR) reported by parents before kindergarten were associated with early cognitive skills at kindergarten and subsequent academic achievement in typically developing children.
\end{abstract}

Method: We followed a community-based sample of 664 French-speaking adolescents from kindergarten (5-6 years) to the end of middle school (15 years). Kindergarten measures included a parental questionnaire aimed at assessing the presence or absence of any kind of LBR, such as storytelling, looking at children's books, reading a story, listening to songs or singing nursery rhymes, as well as family contextual characteristics. Children also performed standardized assessments of oral language, pre-reading skills and non-verbal reasoning. In middle school, children sat a national diploma typically used as an indicator of general academic achievement in Grade 9.

Results: After adjusting for family characteristics, presence of language-based bedtime routines $(57 \%)$ predicted cognitive-academic skills in kindergarten, and were positively associated with academic achievement at Grade 9, related to the beneficial effect on children's vocabulary in kindergarten.

Conclusion: Presence of language-based bedtime routines may provide an indicator of positive parental behavior including exposure to literacy activities, contributing to children's early cognitive development and subsequent academic achievement.

Keywords: Language-based bedtime routines, academic achievement, cognitive-academic skills, family characteristics, follow-up study. 


\section{Statement of contribution}

\section{What is already known on this subject?}

- Family background influences children's academic trajectories early in development;

- Language-based bedtime routines before school entry contribute to language skills in kindergarten;

- These routines might influence later achievement through its effect on early language development;

\section{What does this study add?}

- Language-based bedtime routines were associated with early cognitive-academic skills at kindergarten;

- These routines were linked to academic achievement at the end of middle school (Grade 9);

- This link was related to the beneficial effect of bedtime routines on expressive vocabulary in kindergarten. 


\section{Associations of Language-based Bedtime Routines with Early Cognitive Skills and Academic Achievement: a Follow-Up from Kindergarten to Middle School}

Bedtime routines refer to activities that take place during children's transition from wakefulness to sleep and have been reported to be associated with improved quality in children's sleep (Bates, Viken, Alexander, Beyers, \& Stockton, 2002; Mindell, Li, Sadeh, Kwon, \& Goh, 2015; Sadeh, Gruber, \& Raviv, 2003; Stein, Mendelsohn, Obermeyer, Amromin, \& Benca, 2001), which in turn has been related to children's physical health, cognition and behavior (Buckhalt, El-Sheikh, \& Keller, 2007; El-Sheikh, Buckhalt, Mark Cummings, \& Keller, 2007; Snell, Adam, \& Duncan, 2007). These routines are not exclusively dependent on the family environment, but are shaped by bidirectional transactions between contextual opportunities and requests (e.g. family routines) (Jenni \& O’Connor, 2005) and factors relating to the child (e.g. health and development, individual traits) (Jenni \& LeBourgeois, 2006; Ward, Gay, Alkon, Anders, \& Lee, 2008). Bedtime routines include on the one hand a combination of hygiene-related behaviors (e.g. brushing teeth), receiving good night kisses, putting on night clothes, and caregiver-controlled behaviors centered on language-related activities (i.e. the presence of interactive language-based bedtime routines), on the other (Hale, Berger, LeBourgeois, \& Brooks-Gunn, 2009; Kitsaras, Goodwin, Allan, Kelly, \& Pretty, 2018). The majority of the extant literature in this field of research remains narrowed to the significant associations reported between bedtime routines and sleep (duration, quality). There is limited evidence of the beneficial impact of these routines on children's socio-emotional skills (Spagnola \& Fiese, 2007), cognitive performance (Kelly, Kelly, \& Sacker, 2013) and school readiness (Duncan et al., 2007; Kitsaras et al., 2018). As underlined in the literature review conducted by Mindell and Williamson (2018), research should address the link between specific components of the routines occurring during bedtime and other domains of children's development and wellbeing. 
Language-based bedtime routines (LBR) are informal parent-child interactions involving language, such as reading a book together, storytelling and singing nursery rhymes at bedtime (Hale et al., 2011; Henderson \& Jordan, 2010). Previous research has indicated that shared book reading or storytelling during regular bedtime routines is one of the components of the home literacy environment influencing children's subsequent verbal and cognitive development (Kitsaras et al., 2018). This is in accordance with the well-established influence of shared book reading in the promotion of children's language and psychosocial development (Dowdall et al., 2020; Xie, Chan, Ji, \& Chan, 2018). Indeed, parental reports of home literacy activities (a composite measure which included the mother's implication in LBR) in the first years of life, contributed significantly to the prediction of children's oral language, vocabulary and cognitive skills at ages 3 and 5 years (Rodriguez \& TamisLeMonda, 2011; Rodriguez et al., 2009). The study by Hale and colleagues (2011) has contributed to advancing these findings further by demonstrating the positive association between a specific measure assessing LBR in preschool and children's cognitive skills in kindergarten: the presence of LBR at age 3 years predicted higher children's performances on measures of language ability and receptive vocabulary at 5 years. According to these authors, the magnitude of the association between LBR and children's cognitive development was $50 \%$ greater than the average effects of a year's Head Start for a 4-year-old. Children whose parents include reading as a part of their regular bedtime routines tend to exhibit improved language and reading skills, which in turn translate into better school readiness and a positive impact beyond the first years of school education (Duncan et al., 2007).

To our knowledge, the above-mentioned body of work represents the few reports evidencing an association between the use of language activities as part of regular bedtime routines and children's subsequent developmental outcomes. These studies have pinpointed the hypothetical mechanisms through which LBR have a positive association with children's early language skills, in particular, and a potential cumulative effect for children's 
development, in general. These routines embody informal language and literacy activities stimulating children's early language skills (Sénéchal \& LeFevre, 2002; Whitehurst \& Lonigan, 1998), but they also represent interpersonal interactive opportunities influencing positively children's social-emotional competence (Spagnola \& Fiese, 2007). Further, they typify sleep-promoting practices influencing children's sleep quality (Mindell \& Williamson, 2018), which ultimately have the potential to improve subsequent psychosocial and cognitive development (Duncan et al., 2007; Hale et al., 2011; Rodriguez \& Tamis-LeMonda, 2011). However, the above-mentioned studies were restricted to the period before school entry (Hale et al., 2011), were mainly derived from samples of disadvantaged children, or examined LBR in the context of broader measures reflecting the home literacy environment (Rodriguez \& Tamis-LeMonda, 2011; Rodriguez et al., 2009).

Although previous studies presented evidence of the association between LBR and early language skills in preschool, its association with subsequent academic achievement beyond school entry remains unexplored. Most importantly, LBR are a modifiable feature of the family environment, as opposed to more invariant characteristics (e.g. parental education), through which families can be encouraged to promote early development in their children. Understanding the implications of LBR for children's development provides a fruitful approach to identifying the familial mechanisms that need to be targeted when designing interventions aiming to improve children's development (Kitsaras, Allan, \& Pretty, 2020).

The present study sought to contribute to the extant literature by examining whether the positive association between LBR and early cognitive development is reflected in children's mid-term academic achievement, in a sample of typically developing children followed from age 5 to 15 years and drawn from a community-based population in France. Previous research has presented evidence that the association between certain environmental circumstances and children's development depends on the specificity of their timing and duration (Black et al., 2017; Vandell et al., 2010). We therefore expected that LBR would 
have lasting indirect links to later academic achievement through their significant association with children's cognitive-academic skills at kindergarten. In this sense, we intended to provide an extension to the end of middle school of the findings reported previously by Hale and colleagues (2011).

The aims of the present study were twofold. First, to confirm the degree to which parent-reported use of LBR with their children was associated with children's cognitiveacademic skills in kindergarten, controlling for a number of family background characteristics (e.g. parental education, family structure and size, among others). Second, to investigate the extent to which LBR at kindergarten stage were associated with academic achievement at age 15. We hypothesized that the presence of LBR reported by the parents, such as reading or telling the child stories, would have an effect on children's verbal skills in kindergarten, which in turn would translate into better achievement outcomes at the end of middle school. In addition, we expected that the relation between LBR and children's cognitive-academic skills in kindergarten and academic achievement in middle school would be independent from the effects of a range of family background characteristics.

\section{METHOD}

\section{Participants}

The present report used data from a larger longitudinal study aimed at identifying child- and environmental-level factors related to reading acquisition and academic achievement in a community-based sample followed from kindergarten to the end of middle school (Callu, Jacquier-Roux, Cusin, Giannopulu, \& Dellatolas, 2003; Câmara-Costa, Pulgar, Cusin, \& Dellatolas, 2016; Costa et al., 2013; Doyen et al., 2004; Giannopulu, Escolano, Cusin, Citeau, \& Dellatolas, 2008). This prospective study was conducted in the general population of the Creusot Montceau-les-Mines urban area in the central-eastern region of France. Data was collected for all children attending kindergarten in all preschool classes of the urban area in the 2001-02 school year $(n=921$, ages 5-6 years). To be included in the 
present study, participants were to present data relative to the presence or absence of LBR at kindergarten, and to have available data regarding academic achievement at Grade 9 (2010-11 school year, ages 14-15 years).

This resulted in a final sample of 664 participants (361 boys and 303 girls) with a mean age of 6.95 years $(S D=.32)$ in kindergarten and 15 years $(S D=.29)$ in Grade 9. Sample attrition amounted to $27.9 \%(n=257)$ of the initial kindergarten sample and resulted mainly either from geographical relocation of the participants between kindergarten and middle school, or from missing data regarding LBR and/or academic achievement at Grade 9.

The analysis sample was composed of children and adolescents from diverse sociocultural backgrounds representative of the general population of suburban communities in France, in reference to the national indicators reported by the National Institute of Statistics and Economic Studies (INSEE, 2011a, 2011b, 2011c, 2011d). All participants were attending French-speaking general education classes.

\section{Procedure}

The kindergarten assessments for this study occurred between January and June in 2001. Parents completed a questionnaire pertaining to the socio-demographic characteristics of the child's family, and school doctors performed a standardized examination of each participant individually (the BSEDS, presented below), in accordance with the directives of the French Ministry of Education (Ministère de l'Éducation Nationale, 2002). The systematic application of this measure to kindergarteners involves a short version (screening form), but for the purpose of the present study the complete version was administered. The parental questionnaire and the standardized examination were anonymous for the two trained researchers responsible for data encoding.

At the end of middle school (Grade 9), children sit the "Diplome National du Brevet", a national indicator of academic achievement required by the Ministry of Education (Ministère de l'Éducation Nationale, 2007). Data collection pertaining to these indicators of 
academic achievement (hereafter referred to as Grade 9 outcomes) occurred in July 2011.

Two trained researchers conducted the data collection through the consultation of the database of school records made available by the regional services of the Ministry of Education.

The ethics committee of the National Institute of Health and Medical Research (INSERM) approved this study. In accordance with ethical requirements, and because the participants were legally under the age of consent, parents (or, if not applicable, guardians) and school administrators provided written informed consent and the participants provided verbal informed consent to participate in this study. The regional services of the Ministry of Education were acquainted with the purposes of the study, and approved the access to the school records of the participants in order to collect the Grade 9 outcomes. This study covered a 10-year period of children's academic trajectories, and all information collected at kindergarten and Grade 9 was anonymous to the researchers analysing the data.

\section{Measures}

\section{Kindergarten assessment (2001-2002 school year)}

Family characteristics questionnaire: Parents' responses to the items in this questionnaire were re-coded into nine variables (Câmara-Costa et al., 2016). Eight variables were dichotomous and one ordinal (family size). Language-based bedtime routines (LBR): We asked parents if they "had a regular routine or activity for putting their child asleep, such as 1) telling a story, listening to songs or singing nursery rhymes; 2) looking at children's books or reading a story; and 3) no specific routine or activity". We generated a dichotomous measure of LBR. Parent's responses were coded as "1" for language-based routines whenever they responded positively to at least one of the first two options, and " 0 " if they indicated having no routine or activity for putting their child asleep. Parents' nationality (two variables, for mother and father): French or foreign. Family history of reading difficulties: Presence or absence of history of reading difficulties in at least one first-degree relative. Medical history: Presence or absence of significant health problems in infancy. Family situation: The child 
living with both biological parents vs. other situations (child living with only one parent, living with one of the biological parents and his/her partner or with other relatives or persons). Early childcare (before age 3 years): The child was cared for exclusively by his/her mother before age 3 years $v s$. all other forms of early childcare (informal childcare provided by a relative, by a non-relative, or formal childcare setting, such as day care center). Parental educational level: Final educational level or diploma completed by each parent. We generated a binary variable defining whether parental level of education was low (i.e. neither of the parents had a secondary school diploma) or medium-high (i.e. at least one of the parents obtained a secondary school diploma). Family size: Number of siblings in the household was treated as a continuous variable and ranged from 0 to13.

\section{BSEDS (Bilan de Santé: Evaluation du Développement pour la Scolarité : 5-6 ans):}

The BSEDS battery (Health Examination: Developmental Assessment for Schooling: ages 5-6 years, Zorman \& Jacquier-Roux, 2001) is a standardized assessment that evaluates children's cognitive, motor and social development in kindergarten. As seen in Table 2, this battery comprises 16 subtests (see Giannopulu et al., 2008, for further details). This instrument has good psychometric validity, given the reported reliability and sensitivity of its subtests in identifying children at risk for developing learning difficulties, specifically in the prediction of later reading acquisition ( Costa et al., 2013; Zorman \& Jacquier-Roux, 2001).

\section{Grade 9 assessment (2010-11 school year)}

The Grade 9 diploma is a national indicator of academic achievement at the end of middle school. This diploma comprehends five levels of achievement: "Failure", "Pass", "Satisfactory", "Good" and "Very good". For the purpose of our analyses, the mention "Failure" comprised students that failed the Grade 9 diploma, as well as students that did not sit the diploma in the same year because of repeats of at least one grade between kindergarten and the end of middle school. In addition, we grouped the "Good" and "Very good" levels into the same category (hereafter referred to as "Good/Very good"). These procedures 
generated four homogeneous, comparable groups of middle school outcomes at Grade 9.

\section{Data analysis procedures}

We used the SAS ${ }^{\circledR}$ software version 9 (Statistical Analysis Software, Cary, NC) for data analyses. In the first set of analyses (Tables 1 and 2), we focused on kindergarten associations between LBR, family characteristics and cognitive-academic skills using univariate analyses (chi-square, correlation and $t$-test procedures). As proposed by Cohen (1992), we calculated effect sizes (ES) to estimate the magnitude of associations between variables (chi-square $(w)$ and correlation $(r)$ procedures: small, moderate or large effects, if $w$ or $r=.10, .30$ and .50 , respectively; $t$-test procedures $(d)$ : small, medium and large effects, if $d=.20, .50$ or .80 ). In addition, we performed regression analyses (REG procedure) to explore whether LBR continued to predict different cognitive-academic skills, controlling for the effects of the remaining family characteristics. We adopted a $p<.01$ as the level for statistical significance on all the analytic procedures.

In the second set of analyses (Table 3), we investigated the longitudinal associations between LBR in kindergarten and academic outcomes in Grade 9. We performed univariate analysis (ANOVA) followed by several ordinal logistic regressions (LOGISTIC procedure). These logistic procedures allowed to examine the predictive power of the regression coefficients through the probability of concordance $(c)$ of the model, (i.e. the percentage of pairs of subject in which the subject with the higher observed value also has the higher predicted value), which can be interpreted as a generalized ROC area (Harrell, 2001). In this second set of analyses, we first examined the predictive power of LBR as the only explanatory variable of the Grade 9 outcomes. Second, we examined the predictive power of LBR in explaining the Grade 9 outcomes, also controlling for the simultaneous effects of all other family characteristics. Third, we introduced the variable pertaining to LBR together with the family characteristics and the cognitive-academic skills assessed in kindergarten. Finally, we entered specific cognitive-academic skills (selected based on their links with the 
Grade 9 outcomes) together with all the family characteristics, in order to examine whether the effect of LBR was mediated by specific cognitive-academic skills in kindergarten.

\section{RESULTS}

Preliminary analyses of group comparisons between participants and non-participants indicated no significant differences on any of the demographic and family characteristics $(p>$ .05 , for all the $t$-tests and chi-square procedures used to compare groups). Moreover, we confirmed that there were no significant differences in the main variables of interest between participants with or without missing data in some of the kindergarten measures. Hence, we opted to use the total of participants that presented complete data in each of the measures included in the statistical analyses described subsequently.

\section{Cross-sectional associations of LBR, family characteristics and cognitive academic skills}

\section{in kindergarten}

Table 1 presents baseline socio-demographic, family characteristics and cognitiveacademic skills in kindergarten for the full sample, as well as group comparisons for these variables according to the absence or presence of LBR.

Fifty-seven percent of the parents indicated the presence of LBR. These routines were significantly associated with parental nationality, type of early childcare, parental educational level and family size. Absence of LBR was more frequently reported by parents from families whose at least one of the parents was of foreign nationality, when early childcare was provided exclusively by the mother, when parental educational level was low and when family size was large. The magnitude of the associations between these family characteristics and LBR ranged from small (mother's nationality, $w=.10)$ to moderate (parental educational level, $w=.31$ ). There were no significant differences in reports of LBR according to a family history of reading difficulties, the child's medical history or family situation.

Seven of the 16 subtests that make up the BSEDS battery were significantly associated with LBR (Table 2). Children whose families reported the presence of LBR tended to 
evidence higher performances in the subtests of Expressive and Receptive vocabulary, Oral comprehension, Word and Sentence Repetition, Digit Span and Figure Reproduction. None of the remaining subtests in the $B S E D S$ battery showed significant differences (at $p<.01$ ) according to the presence or absence of LBR.

Regression analyses performed individually for each of the seven BSEDS subtests controlling for the effects of LBR and all family characteristics indicated that LBR remained significantly predictive of children's performances in the subtests of Expressive and Receptive vocabulary, Oral Comprehension and Sentence Repetition ( $p<.01$, for all cases). For the other subtests (i.e. Word Repetition, Digit Span and Figure Reproduction), the predictive power of LBR was no longer significant, over and above the effects of the remaining family characteristics in kindergarten (marginal $p$ values for the Word Repetition and the Digit Span subtests; $p=.07$ and $p=.06$, respectively).

\section{Longitudinal associations of LBR, family characteristics and cognitive-academic skills in kindergarten with academic achievement in Grade 9}

The data collected at Grade 9 indicated that 222 (33.4\%) of the participants "Failed" to obtain the national diploma at the end of middle school, $133(20 \%)$ "Passed" their diploma with no particular distinction, 146 (21.9\%) evidenced a "Satisfactory" performance and 163 $(24.5 \%)$ obtained "Good/Very good" marks. Figure 1 shows the percentage of children whose families indicated the use of LBR in relation to the four levels of the Grade 9 outcomes. There was a clear tendency for the presence of LBR to be associated with better achievement at Grade 9 and the magnitude of this effect was moderate $(w=.21, p<.001)$.

As shown in Table 3, the results of the first logistic regression (Model 1) confirmed that LBR alone were significantly predictive of the Grade 9 outcomes, with a percentage of concordance $(c)$ of $32.5 \%$. The inclusion of the measures pertaining to family characteristics (Model 2) contributed to increasing the percentage of concordance to 66.5\%. In this model, LBR continued to predict significantly the Grade 9 outcomes, over and above the effects of 
the remaining family characteristics assessed in kindergarten, namely the father's nationality, family history of reading difficulties, medical history, family situation, early childcare and parental educational level. Supplementary regression analyses evidenced that the interaction terms between LBR and family characteristics (i.e. parental nationality, parental educational level, family size and type of early childcare) were not significant in predicting the Grade 9 outcomes.

Regarding the associations between the BSEDS subtests and the Grade 9 outcomes, additional logistic regression analyses indicated that four subtests, namely Expressive vocabulary, Word repetition, Letter recognition and Figure reproduction, remained significant predictors of the Grade 9 outcomes ( $p<.01$, for all cases), after controlling for the effect of all other subtests and family characteristics in kindergarten (Model 3). In addition, family situation and parental educational level added to the prediction of the Grade 9 outcomes, beyond the effects of the remaining family characteristics and BSEDS subtests. The percentage of concordance increased to $77.8 \%$ in this regression model, after controlling for all family characteristics and all the $16 B S E D S$ subtests as predictors of the Grade 9 outcomes. For the purpose of simplicity, we present in Table 3 only the results for the four subtests that were significant predictors of the Grade 9 outcomes in Model 3, although we included in this regression model all the 16 subtests from the BSEDS battery together with all the family characteristics in kindergarten.

In the final step of the logistic regression analyses, we entered each of the four subtests that were significantly predictive of the Grade 9 outcomes independently into separate models, together with all the family characteristics assessed in kindergarten. The effect of LBR was no longer significant when the subtest Expressive vocabulary was introduced into the model (Model 4), but it remained significant when the children's performances on each of the other three subtests (i.e., Word repetition, Letter recognition and Figure reproduction) were taken into account. 


\section{DISCUSSION}

Parental reports of language-related activities at bedtime were associated with children's cognitive-academic skills in kindergarten, and with academic achievement at the end of middle school, after controlling for several family factors. The longitudinal association of LBR with academic achievement at Grade 9 was no longer significant, once expressive vocabulary in kindergarten was controlled. This particular result points to the positive influence of LBR on children's vocabulary in kindergarten, which translates into lasting indirect effects to children's subsequent academic achievement. Furthermore, among the family factors, only parental education and family situation were associated with mid-term academic achievement after controlling for cognitive performance in kindergarten. Finally, the absence of LBR was associated with foreign nationality of at least one parent, absence of formal early childcare, lower parental educational levels and large family size.

\section{LBR and oral language development in kindergarten}

The association between LBR and children's vocabulary confirms the results from previous studies (Hale et al., 2011; Rodriguez \& Tamis-LeMonda, 2011; Rodriguez et al., 2009). LBR amount to a form of informal language and literacy experience exposing children to oral and/or written language, which has been shown to promote children's early receptive language skills and vocabulary acquisition (Raikes et al., 2006; Sénéchal \& LeFevre, 2002; Sénéchal, LeFevre, Hudson, \& Lawson, 1996). Our findings add to these previous studies by confirming the significant role of LBR in children's verbal skills, not only among children from disadvantaged families, but also in a sample of typically developing children drawn from a French community-based population attending general education classrooms.

Informal language and literacy activities, such as LBR, could play a specific role in oral language and vocabulary acquisition (Rodriguez \& Tamis-LeMonda, 2011), as opposed to the development of emergent literacy skills, such as letter identification, which tend to 
relate more closely to formal literacy experiences focused exclusively on written language (Sénéchal, LeFevre, Thomas, \& Daley, 1998; Whitehurst \& Lonigan, 1998).

The positive correlation observed in the current study between LBR and language skills in kindergarten, does not inform on its own about causality. It is possible that LBR improve language skills in kindergarten, but also that children's language skills contribute to the presence and sustenance of LBR. Bedtime routines centered around language-related activities illustrate Bronfenbrenner's proximal processes (Bronfenbrenner, 1979; Bronfenbrenner \& Morris, 2006), in which developmental outcomes are a consequence of the dynamic interplay between children and their environments. In this sense, LBR result both from environmental opportunities, as well as from individual demands from the child himself (Fukuda \& Sakashita, 2002; Jenni \& LeBourgeois, 2006; Jenni \& O’Connor, 2005).

However, we suggest that this potential bidirectionalilty is asymmetrical: the probability of one direction of the effects (i.e. LBR improving expressive language) is greater than the probability of the opposite direction (i.e. expressive language influencing the occurrence of LBR). First, although we assessed LBR in kindergarten, we consider that parent's responses in kindergarten mainly refer to the broader preschool period that precedes formal learning to read. Second, findings reported in previous research have evidenced a causality according to which LBR at age 3 years improve children's language skills at age 5 years (Hale et al., 2011). Third, children's language skills on their own cannot completely account for the presence of LBR, which are determined to some extent by parental initiative and involvement.

\section{LBR as an indicator of family literacy environment and positive parental behavior}

The assessment measure used in the present study was based on one specific question aiming to identify interactive LBR, such as storytelling, reading a story, listening to songs or singing nursery rhymes. These activities are assumed to be a proxy of the broader home-based family literacy environment (literacy activities, parental involvement, provision of learning 
materials) (Rodriguez \& Tamis-LeMonda, 2011; Rodriguez et al., 2009), and an indicator of overall positive parental behaviors (Hale et al., 2011). In this sense, LBR seem to provide an estimate of interactive and stimulating family environments (Rodriguez \& Tamis-LeMonda, 2011; Rodriguez et al., 2009).

As advanced by Hale and colleagues (2011), LBR could reflect parental emotional availability in accompanying these practices, which helps the child feel safe in a controllable environment. These routines also tend to be associated with other positive parental behaviors, such as putting the child to bed at a regular time or providing increased levels of language stimulation. Previous studies have evidenced that the presence of bedtime routines contribute to strengthen parent-child relationships (Spagnola \& Fiese, 2007).

\section{LBR and mid-term academic achievement}

Our results indicated that LBR have lasting consequences for children's mid-term academic achievement, through their influence on children's vocabulary in kindergarten. This finding provides an extension of previous results reported in kindergarten (Hale et al., 2011; Rodriguez \& Tamis-LeMonda, 2011; Rodriguez et al., 2009). The positive link between LBR and children's vocabulary in kindergarten might carry lasting implications for subsequent achievement, since vocabulary has been consistently highlighted as a robust predictor of later achievement in elementary school and beyond (Cunningham \& Stanovich, 1997; Duncan et al., 2007; Pagani, Fitzpatrick, Archambault, \& Janosz, 2010; Romano, Babchishin, Pagani, \& Kohen, 2010).

Our findings also underscore the importance of the timing of certain contextual influences on children's development. In the present study, only parental education and family situation remained significant predictors of the Grade 9 outcomes, once the effects of children's cognitive-academic skills in kindergarten were controlled for, in accordance with previous findings (Bornstein, Hahn, \& Wolke, 2013; Boyle, Georgiades, Racine, \& Mustard, 2007; Georgiades, Boyle, \& Duku, 2007; Pagani et al., 2008). Hence, while some family 
characteristics exert their influence throughout children's achievement trajectories (e.g. parental educational level, family situation), the contribution of other characteristics, such as LBR, could be significantly stronger in specific periods of children's development, namely preschool and kindergarten (Black et al., 2017; Schoon et al., 2002).

\section{Family correlates of language-based bedtime routines}

The findings here reported provide insight into the family correlates associated with the use of bedtime routines based on interactive linguistic exchanges. The absence of LBR reported by the parents was frequently observed in children whose family characteristics included at least one parent of foreign nationality, who had not been enrolled in formal early childcare, whose parental educational levels were low and with a large number of siblings. Poverty, low maternal education and larger household sizes have been previously pointed to as demographic predictors associated with lesser use of interactive parent-child bedtime routines (Hale et al., 2009) and with a lower frequency of parental reports of reading to their child (Kuo, Franke, Regalado, \& Halfon, 2004; Roberts, Jurgens, \& Burchinal, 2005). The percentage of parental reports of language-related bedtime routines found in previous research (Rodriguez et al., 2009) with children from low-income families (38\%), is lower than the one reported in the present work (57\%) and the study (56\%) by Hale and colleagues (2011). The lower frequency of LBR observed in disadvantaged families could be associated with fewer resources and developmental opportunities (Gutman, Sameroff, \& Cole, 2003; McLoyd, 1998; Pungello et al., 2010; Schoon et al., 2002; Vandell et al., 2010). Importantly, our results suggest the family factors that might contribute to facilitate (or hinder) the promotional role of LBR in potentiating children's development. It is important to denote, however, that in the present study we found no evidence of an interaction between LBR and the remaining family characteristics in predicting the achievement outcomes at the end of middle school. 
RUNNING HEAD: Bedtime routines and academic achievement

\section{Limitations and strengths}

The sample used in the present study is nationally representative of suburban and rural communities in France, which limits the generalizability of these results to children from urban areas. However, the participants' performances in the Grade 9 academic outcomes paralleled the nationally-representative results reported by the French Ministry of Education (Ministère de l’Éducation Nationale, 2012). Additionally, our measure of LBR relied on a single question covering several types of language-based bedtime practices, which hindered exploratory analyses on the specific associations of the different dimensions of languagebased practices included in these routines. This measure also did not allow examining the frequency, regularity, continuity and evolution of these language-based routines in the household. The lack of specificity of the period where these LBR took place might have contributed to the risk of reported bias. Future studies using a more detailed questionnaire aiming at uncovering different practices of language-based bedtime routines, as well as their frequency, regularity, and continuity, could contribute to confirm the present findings. Further to this, the inclusion of additional home-based family literacy and language activities, would have contributed to discriminate between LBR and the broader literacy environment in the home, as well as to control more precisely for the association between LBR, early language and subsequent academic achievement. Parental educational level was dichotomous, which may have contributed to curtailing the proportion of variance explained by this variable in children's outcomes.

Nevertheless, a number of strengths support the validity and reliability of the findings reported here. The sample size was considerable and drawn from a representative population of typically developing children enrolled in general education classrooms of suburban communities in France. The study covered an extended period from kindergarten to the end of middle school. Finally, the analyses investigated a comprehensive and unique set of early 
child and family-related measures as plausible predictors of a nationally representative measure of middle school outcomes over a 10-year time span.

\section{Conclusion}

Familial factors relating to parental education, family situation, and type of early childcare are major environmental correlates of children's academic achievement in France (Câmara-Costa et al., 2016) and other countries (Côté et al., 2013; Geoffroy et al., 2010; OECD, 2016; Reynolds, Ou, \& Topitzes, 2004; Sameroff, Seifer, Baldwin, \& Baldwin, 1993). The findings of the present study draw attention to an additional family correlate of children's early language development and subsequent academic achievement. Because previous intervention studies have demonstrated that programs aiming to promote book-sharing and bedtime routines in low-income families increased parental participation in child-centered book-related activities (High, Hopmann, LaGasse, \& Linn, 1998), LBR could be a fruitful approach for intervening with parents, on account of their flexible nature, the few constraints and low costs they involve for parents, educators and practitioners. The implementation of LBR is a modifiable feature of the family environment that practitioners can suggest to parents as a means of stimulating children's cognitive-linguistic acquisitions. 


\section{References}

Bates, J. E., Viken, R. J., Alexander, D. B., Beyers, J., \& Stockton, L. (2002). Sleep and Adjustment in Preschool Children : Sleep Diary Reports by Mothers Relate to Behavior Reports by Teachers. Child Development, 73(1), 62-75. doi: 10.1111/14678624.00392

Black, M. M., Walker, S. P., Fernald, L. C. H., Andersen, C. T., DiGirolamo, A. M., Lu, C., ... Grantham-McGregor, S. (2017). Early childhood development coming of age : Science through the life course. The Lancet, 389(10064), 77-90. doi: 10.1016/S01406736(16)31389-7

Bornstein, M. H., Hahn, C.-S., \& Wolke, D. (2013). Systems and cascades in cognitive development and academic achievement. Child Development, 84(1), 154-162. doi: 10.1111/j.1467-8624.2012.01849.x

Boyle, M. H., Georgiades, K., Racine, Y., \& Mustard, C. (2007). Neighborhood and Family Influences on Educational Attainment : Results from the Ontario Child Health Study Follow-Up 2001. Child Development, 78(1), 168-189. doi: 10.1111/j.14678624.2007.00991.x

Bronfenbrenner, U. (1979). The ecology of human development. Cambridge, MA: Harvard University Press.

Bronfenbrenner, U., \& Morris, P. A. (2006). The bioecological model of human development. In W. Damon \& R. M. Lerner (Éds.), Handbook of child psychology : Vol. 1. Theoretical models of human development (6th éd., Vol. 1, p. 793-828). Hoboken: Wiley.

Buckhalt, J. A., El-Sheikh, M., \& Keller, P. (2007). Children's sleep and cognitive functioning : Race and socioeconomic status as moderators of effects. Child Development, 78(1), 213-231. doi: 10.1111/j.1467-8624.2007.00993.x

Callu, D., Jacquier-Roux, M., Cusin, F., Giannopulu, I., \& Dellatolas, G. (2003). Pertinence du repérage par les parents des retards de langage chez l'enfant entre quatre et six ans [Pertinence of parental screening for delays of language in children aged four to six years]. Archives De Pédiatrie, 10(12), 1061-1067.

Câmara-Costa, H., Pulgar, S., Cusin, F., \& Dellatolas, G. (2016). Facteurs associés aux difficultés scolaires : Une étude de suivi de la maternelle à la fin du collège [Preschool familial environment and academic difficulties: A 10-year follow-up from kindergarten to middle school]. Archives de Pédiatrie, 23(2), 136-142. doi: 10.1016/j.arcped.2015.11.007

Cohen, J. (1992). A power primer. Psychological Bulletin, 112(1), 155-159. https://doi.org/10.1037//0033-2909.112.1.155

Costa, H. C., Perdry, H., Soria, C., Pulgar, S., Cusin, F., \& Dellatolas, G. (2013). Emergent literacy skills, behavior problems and familial antecedents of reading difficulties : A follow-up study of reading achievement from kindergarten to fifth grade. Research in Developmental Disabilities, 34(3), 1018-1035. doi: 10.1016/j.ridd.2012.11.029

Côté, S. M., Mongeau, C., Japel, C., Xu, Q., Séguin, J. R., \& Tremblay, R. E. (2013). Child Care Quality and Cognitive Development : Trajectories Leading to Better Preacademic Skills. Child Development, 84(2), 752-766. doi: 10.1111/cdev.12007

Cunningham, A. E., \& Stanovich, K. E. (1997). Early reading acquisition and its relation to reading experience and ability 10 years later. Developmental Psychology, 33(6), 934-945. 
Dowdall, N., Melendez-Torres, G. J., Murray, L., Gardner, F., Hartford, L., \& Cooper, P. J. (2020). Shared Picture Book Reading Interventions for Child Language Development : A Systematic Review and Meta-Analysis. Child Development, 91(2). doi: $10.1111 /$ cdev.13225

Doyen, A. L., Giannopulu, I., Escolano, S., Cusin, F., Jacquier-Roux, M., \& Dellatolas, G. (2004). Antécédents parentaux de difficultés langagières et évaluation du langage chez l'enfant entre cinq et six ans. [Parental antecedents of language problems and langage evaluation in five and six-year-old children]. Archives de Pédiatrie, 11(10), 1249-1250. doi: 10.1016/j.arcped.2004.06.037

Duncan, G. J., Dowsett, C. J., Claessens, A., Magnuson, K., Huston, A. C., Klebanov, P., ... Japel, C. (2007). School readiness and later achievement. Developmental Psychology, 43(6), 1428-1446. doi: 10.1037/0012-1649.43.6.1428

El-Sheikh, M., Buckhalt, J. A., Mark Cummings, E., \& Keller, P. (2007). Sleep disruptions and emotional insecurity are pathways of risk for children. Journal of Child Psychology and Psychiatry, 48(1), 88-96. doi: 10.1111/j.1469-7610.2006.01604.x

Fukuda, K., \& Sakashita, Y. (2002). Sleeping pattern of kindergartners and nursery school children : Function of daytime nap. Perceptual and Motor Skills, 94(1), 219-228. doi: 10.2466/pms.2002.94.1.219

Geoffroy, M.-C., Côté, S. M., Giguère, C.-É., Dionne, G., Zelazo, P. D., Tremblay, R. E., ... Séguin, J. R. (2010). Closing the gap in academic readiness and achievement: The role of early childcare. Journal of Child Psychology and Psychiatry, and Allied Disciplines, 51(12), 1359-1367. doi: 10.1111/j.1469-7610.2010.02316.x

Georgiades, K., Boyle, M. H., \& Duku, E. (2007). Contextual influences on children's mental health and school performance: The moderating effects of family immigrant status. Child Development, 78(5), 1572-1591. doi: 10.1111/j.1467-8624.2007.01084.x

Giannopulu, I., Escolano, S., Cusin, F., Citeau, H., \& Dellatolas, G. (2008). Teachers' reporting of behavioural problems and cognitive-academic performances in children aged 5-7 years. The British Journal of Educational Psychology, 78(Pt 1), 127-147. doi: 10.1348/000709907X204372

Gutman, L. M., Sameroff, A. J., \& Cole, R. (2003). Academic growth curve trajectories from 1st grade to 12th grade : Effects of multiple social risk factors and preschool child factors. Developmental Psychology, 39(4), 777-790.

Hale, L., Berger, L. M., LeBourgeois, M. K., \& Brooks-Gunn, J. (2009). Social and Demographic Predictors of Preschoolers' Bedtime Routines: Journal of Developmental \& Behavioral Pediatrics, 30(5), 394-402. doi: 10.1097/DBP.0b013e3181ba0e64

Hale, L., Berger, L. M., LeBourgeois, M. K., \& Brooks-Gunn, J. (2011). A longitudinal study of preschoolers' language-based bedtime routines, sleep duration, and well-being. Journal of Family Psychology: JFP: Journal of the Division of Family Psychology of the American Psychological Association (Division 43), 25(3), 423-433. doi: 10.1037/a0023564

Harrel Jr, F. E. (2001). Regression modeling strategies with applications to linear models, logistic regression, and survival analysis. New York: Springer.

Henderson, J. A., \& Jordan, S. S. (2010). Development and Preliminary Evaluation of the Bedtime Routines Questionnaire. Journal of Psychopathology and Behavioral Assessment, 32(2), 271-280. https://doi.org/10.1007/s10862-009-9143-3 
High, P., Hopmann, M., LaGasse, L., \& Linn, H. (1998). Evaluation of a clinic-based program to promote book sharing and bedtime routines among low-income urban families with young children. Archives of Pediatrics \& Adolescent Medicine, 152(5), 459-465.

Institut National de la Statistique et des Études Économiques. (2011a). Chiffres clés Diplômes-Formation EPCI de la CU Le Creusot-Montceau-les Mines [Key figures Diplomas-Formation-Creusot Montceau-les Mines community]. http://www.insee.fr/fr/themes/tableau_local.asp?ref_id=FOR\&nivgeo=EPCI\&codgeo $=247100290 \&$ millesime $=2010$

Institut National de la Statistique et des Études Économiques. (2011b). Chiffres clés Diplômes-Formation-France [Key figures Diplomas-Formation-France]. http://www.insee.fr/fr/themes/tableau_local.asp?ref_id=FOR\&nivgeo=FE\&codgeo=1 \&millesime $=2010$

Institut National de la Statistique et des Études Économiques. (2011c). Chiffres clés Évolution et structure de la population-EPCI de la CU Le Creusot-Montceau les Mines [Key figures Evolution and structure of the population-Creusot Montceau-les Mines community].

http://www.insee.fr/fr/themes/tableau_local.asp?ref_id=POP\&nivgeo=EPCI\&codgeo= $247100290 \&$ millesime $=2010$

Institut National de la Statistique et des Études Économiques. (2011d). Chiffres clés Évolution et structure de la population-France [Key figures Evolution and structure of the population-France].

http://www.insee.fr/fr/themes/tableau_local.asp?ref_id=POP\&millesime=2010\&nivge $\mathrm{o}=\mathrm{FE} \& \operatorname{codge} \mathrm{o}=1$

Jenni, O. G., \& LeBourgeois, M. K. (2006). Understanding sleep-wake behavior and sleep disorders in children : The value of a model: Current Opinion in Psychiatry, 19(3), 282-287. doi: 10.1097/01.yco.0000218599.32969.03

Jenni, O. G., \& O'Connor, B. B. (2005). Children's sleep : An interplay between culture and biology. Pediatrics, 115(1 Suppl), 204-216. doi: 10.1542/peds.2004-0815B

Kelly, Y., Kelly, J., \& Sacker, A. (2013). Time for bed: Associations with cognitive performance in 7-year-old children: a longitudinal population-based study. Journal of Epidemiology and Community Health, 67(11), 926-931. doi: 10.1136/jech-2012202024

Kitsaras, G., Allan, J., \& Pretty, I. A. (2020). Bedtime Routines Intervention for Children (BRIC) using an automated text messaging system for behaviour change : Study protocol for an early phase study. Pilot and Feasibility Studies, 6(1), 14. doi: 10.1186/s40814-020-0562-y

Kitsaras, G., Goodwin, M., Allan, J., Kelly, M. P., \& Pretty, I. A. (2018). Bedtime routines child wellbeing \& development. BMC Public Health, 18(1), 386. doi: 10.1186/s12889-018-5290-3

Kuo, A. A., Franke, T. M., Regalado, M., \& Halfon, N. (2004). Parent report of reading to young children. Pediatrics, 113(6 Suppl), 1944-1951.

McLoyd, V. C. (1998). Socioeconomic disadvantage and child development. The American Psychologist, 53(2), 185-204.

Mindell, J. A., Li, A. M., Sadeh, A., Kwon, R., \& Goh, D. Y. T. (2015). Bedtime Routines for Young Children : A Dose-Dependent Association with Sleep Outcomes. Sleep, 38(5), 717-722. doi: $10.5665 /$ sleep.4662 
Mindell, J. A., \& Williamson, A. A. (2018). Benefits of a bedtime routine in young children : Sleep, development, and beyond. Sleep Medicine Reviews, 40, 93-108. doi: 10.1016/j.smrv.2017.10.007

Ministère de l'Éducation Nationale. (2002). Circulaire n 2002-024 du 31 janvier 2002 relative à la mise en œuvre d'un plan d'action pour les enfants atteints d'un trouble spécifique du langage oral ou écrit. [Circular No. 2002-024 of 31 January 2002 on the implementation of an action plan for children with a specific problem of oral or written]. Bulletin Officiel, (n ${ }^{\circ} 6,7$ février 2002), I à XI.

Ministère de l'Éducation Nationale. (2007). Décret $n^{\circ}$ 2007-921 du 15 mai 2007 relatif au diplôme national du brevet et modifiant le code de l'éducation. [Decree No. 2007-921 of 15 May 2007 on the national diploma and amending the education code]. Journal Officiel de la République Française, (n¹13, 16 mai 2007), 9199.

Ministère de l'Éducation Nationale - Département de l'Évaluation, de la Prospective et de la Performance. (2012). Diplôme national du brevet Session 2011 : Une réussite qui se stabilise [Diplôme national du brevet 2011 Session : An achievement that tends to stabilize]. Note d'information 12. 02, MEN-DEPP, 1-6.

Organization for Economic Co-operation and Development (OECD). (2016). Low-Performing Students : Why They Fall Behind and How to Help Them Suceed, PISA. Paris: OECD Publishing. http://dx.doi.org/10.1787/97892642502046-en

Pagani, L. S., Fitzpatrick, C., Archambault, I., \& Janosz, M. (2010). School readiness and later achievement : A French Canadian replication and extension. Developmental Psychology, 46(5), 984-994. doi: 10.1037/a0018881

Pagani, L. S., Vitaro, F., Tremblay, R. E., McDuff, P., Japel, C., \& Larose, S. (2008). When Predictions Fail : The Case of Unexpected Pathways Toward High School Dropout. Journal of Social Issues, 64(1), 175-194. doi: 10.1111/j.1540-4560.2008.00554.x

Pungello, E. P., Kainz, K., Burchinal, M., Wasik, B. H., Sparling, J. J., Ramey, C. T., \& Campbell, F. A. (2010). Early educational intervention, early cumulative risk, and the early home environment as predictors of young adult outcomes within a high-risk sample. Child Development, 81(1), 410-426. doi: 10.1111/j.1467-8624.2009.01403.x

Raikes, H., Pan, B. A., Luze, G., Tamis-LeMonda, C. S., Brooks-Gunn, J., Constantine, J., ... Rodriguez, E. T. (2006). Mother-child bookreading in low-income families : Correlates and outcomes during the first three years of life. Child Development, 77(4), 924-953. doi: 10.1111/j.1467-8624.2006.00911.x

Reynolds, A. J., Ou, S.-R., \& Topitzes, J. W. (2004). Paths of Effects of Early Childhood Intervention on Educational Attainment and Delinquency: A Confirmatory Analysis of the Chicago Child-Parent Centers. Child Development, 75(5), 1299-1328. doi: 10.1111/j.1467-8624.2004.00742.x

Roberts, J., Jurgens, J., \& Burchinal, M. (2005). The role of home literacy practices in preschool children's language and emergent literacy skills. Journal of Speech, Language, and Hearing Research: JSLHR, 48(2), 345-359. doi: 10.1044/10924388(2005/024)

Rodriguez, E. T., \& Tamis-LeMonda, C. S. (2011). Trajectories of the Home Learning Environment Across the First 5 Years : Associations With Children's Vocabulary and Literacy Skills at Prekindergarten: Trajectories of the Home Learning Environment. Child Development, 82(4), 1058-1075. doi: 10.1111/j.1467-8624.2011.01614.x

Rodriguez, E. T., Tamis-LeMonda, C. S., Spellmann, M. E., Pan, B. A., Raikes, H., Lugo-Gil, J., \& Luze, G. (2009). The formative role of home literacy experiences across the first 
three years of life in children from low-income families. Journal of Applied Developmental Psychology, 30(6), 677-694. doi: 10.1016/j.appdev.2009.01.003

Romano, E., Babchishin, L., Pagani, L. S., \& Kohen, D. (2010). School readiness and later achievement : Replication and extension using a nationwide Canadian survey. Developmental Psychology, 46(5), 995-1007. doi: 10.1037/a0018880

Sadeh, A., Gruber, R., \& Raviv, A. (2003). The effects of sleep restriction and extension on school-age children: What a difference an hour makes. Child Development, 74(2), 444-455.

Sameroff, A. J., Seifer, R., Baldwin, A., \& Baldwin, C. (1993). Stability of intelligence from preschool to adolescence: The influence of social and family risk factors. Child Development, 64(1), 80-97.

Schoon, I., Bynner, J., Joshi, H., Parsons, S., Wiggins, R. D., \& Sacker, A. (2002). The influence of context, timing, and duration of risk experiences for the passage from childhood to midadulthood. Child Development, 73(5), 1486-1504.

Sénéchal, M., \& LeFevre, J.-A. (2002). Parental involvement in the development of children's reading skill : A five-year longitudinal study. Child Development, 73(2), 445-460.

Sénéchal, M., LeFevre, J.-A., Hudson, E., \& Lawson, E. P. (1996). Knowledge of storybooks as a predictor of young children's vocabulary. Journal of Educational Psychology, 88(3), 520-536. doi: 10.1037/0022-0663.88.3.520

Sénéchal, M., LeFevre, J.-A., Thomas, E. M., \& Daley, K. E. (1998). Differential Effects of Home Literacy Experiences on the Development of Oral and Written Language. Reading Research Quarterly, 33(1), 96-116. doi: 10.1598/RRQ.33.1.5

Snell, E. K., Adam, E. K., \& Duncan, G. J. (2007). Sleep and the body mass index and overweight status of children and adolescents. Child Development, 78(1), 309-323. doi: 10.1111/j.1467-8624.2007.00999.x

Spagnola, M., \& Fiese, B. H. (2007). Family Routines and Rituals : A Context for Development in the Lives of Young Children. Infants \& Young Children, 20(4), 284-299. doi: 10.1097/01.IYC.0000290352.32170.5a

Stein, M. A., Mendelsohn, J., Obermeyer, W. H., Amromin, J., \& Benca, R. (2001). Sleep and behavior problems in school-aged children. Pediatrics, 107(4), E60.

Vandell, D. L., Belsky, J., Burchinal, M., Steinberg, L., Vandergrift, N., \& NICHD Early Child Care Research Network. (2010). Do effects of early child care extend to age 15 years? Results from the NICHD study of early child care and youth development. Child Development, 81(3), 737-756. doi: 10.1111/j.1467-8624.2010.01431.x

Ward, T. M., Gay, C., Alkon, A., Anders, T. F., \& Lee, K. A. (2008). Nocturnal Sleep and Daytime Nap Behaviors in Relation to Salivary Cortisol Levels and Temperament in Preschool-Age Children Attending Child Care. Biological Research For Nursing, 9(3), 244-253. doi: 10.1177/1099800407310158

Whitehurst, G. J., \& Lonigan, C. J. (1998). Child development and emergent literacy. Child Development, 69(3), 848-872.

Xie, Q.-W., Chan, C. H. Y., Ji, Q., \& Chan, C. L. W. (2018). Psychosocial Effects of ParentChild Book Reading Interventions : A Meta-analysis. Pediatrics, 141(4). doi: 10.1542/peds.2017-2675

Zorman, M., \& Jacquier-Roux, M. (2001). BSEDS 5-6 : Bilan de Santé Évaluation du Développement pour la Scolarité 5 à 6 ans-Version 2 [Health Examination : Developmental assessment for school children aged 5-6 years-2nd version]. Grenoble: Laboratoire Cognisciences, IUFM de Grenoble. 


\section{Table 1}

Socio-demographic and family characteristics of the full analytic sample and group comparisons in kindergarten according to the presence or absence of languagebased bedtime routines

\begin{tabular}{|c|c|c|c|c|c|c|c|c|}
\hline \multirow[b]{3}{*}{ Age at kindergarten: mean (SD) [Range] } & \multicolumn{7}{|c|}{ Language-based bedtime routines } & \multirow{3}{*}{$\begin{array}{c}\text { ES } \\
d=.12\end{array}$} \\
\hline & \multicolumn{4}{|c|}{ Full sample } & \multicolumn{2}{|c|}{ Absence (43\%) } & Presence $(57 \%)$ & \\
\hline & 664 & 5.59 & (.3) & [4.9-6.9] & 5.57 & (.3) & 5.61 & \\
\hline Age at Grade 9: mean (SD) [Range] & 664 & 15 & $(.3)$ & {$[14.7-15.5]$} & 14.99 & $(.3)$ & 15.01 & $d=.08$ \\
\hline Family size: mean (SD) [Range] & 654 & 1.6 & $(1.3)$ & {$[0-13]$} & 1.83 & $(1.4)$ & $1.44 \quad(1.1)$ & $d=.31 * * *$ \\
\hline Male $(\%)$ & 664 & 54.4 & & & 54.0 & & 54.6 & $w=.006$ \\
\hline Father's nationality: $\%$ of foreign fathers & 636 & 11.0 & & & 16.0 & & 7.2 & $w=.14 * * *$ \\
\hline Mother's nationality: $\%$ of foreign mothers & 639 & 9.6 & & & 13.0 & & 6.9 & $w=.10^{* *}$ \\
\hline Family history of reading difficulties: $\%$ yes & 626 & 18.4 & & & 18.9 & & 17.9 & $w=.01$ \\
\hline Medical history: \% of significant health problems & 639 & 6.6 & & & 7.3 & & 6.0 & $w=.03$ \\
\hline Family situation: $\%$ children not living with both parents & 651 & 14.4 & & & 15.7 & & 13.5 & $w=.03$ \\
\hline Early childcare: $\%$ of exclusively maternal care & 653 & 49.6 & & & 57.5 & & 43.7 & $w=.14 * * *$ \\
\hline Parental educational level: \% low & 646 & 50.9 & & & 63.9 & & 41.2 & $w=.23 * * *$ \\
\hline
\end{tabular}

$d$. Cohen's $d ; w$. Omega from chi-square test; ES. Effect sizes; ** $p<.01 ; * * * p<.001$. 


\section{Table 2}

Cognitive academic skills of the full analytic sample and group comparisons in kindergarten according to the presence or absence of language-based bedtime routines

\begin{tabular}{|c|c|c|c|c|c|c|c|c|c|}
\hline & \multicolumn{8}{|c|}{ Language-based bedtime routines } & \multirow[b]{3}{*}{$\mathbf{E S}$} \\
\hline & \multicolumn{4}{|c|}{ Full sample } & \multicolumn{2}{|c|}{ Absence } & \multicolumn{2}{|c|}{ Presence } & \\
\hline & $\mathbf{N}$ & Mean & SD & Range & Mean & SD & Mean & SD & \\
\hline \multicolumn{10}{|l|}{ Cognitive academic skills } \\
\hline Rhymes & 660 & 5.09 & 2.54 & $0-8$ & 4.99 & 2.54 & 5.16 & 2.55 & $d=.07$ \\
\hline Syllabic counting & 662 & 4.38 & 1.17 & $0-5$ & 4.37 & 1.25 & 4.38 & 1.11 & $d=.007$ \\
\hline Syllabic deletion & 661 & 6.10 & 3.54 & $0-10$ & 5.86 & 3.49 & 6.29 & 3.57 & $d=.12$ \\
\hline Expressive vocabulary & 653 & 9.34 & 4.18 & $0-25$ & 8.59 & 4.06 & 9.89 & 4.18 & $d=.32 * * *$ \\
\hline Receptive vocabulary & 660 & 19.19 & 3.87 & $1-28$ & 18.41 & 4.04 & 19.76 & 3.64 & $d=.35 * * *$ \\
\hline Oral comprehension & 660 & 7.54 & 1.75 & $1-10$ & 7.22 & 1.91 & 7.77 & 1.59 & $d=.32 * * *$ \\
\hline Word repetition & 664 & 8.44 & 1.76 & $0-10$ & 8.22 & 1.85 & 8.59 & 1.68 & $d=.22 * *$ \\
\hline Pseudo-word repetition & 663 & 8.91 & 1.54 & $0-10$ & 8.79 & 1.77 & 8.99 & 1.64 & $d=.13$ \\
\hline Sentence repetition & 662 & 13.66 & 2.99 & $0-16$ & 13.09 & 3.26 & 14.09 & 2.69 & $d=.34 * * *$ \\
\hline Rapid naming (seconds) & 658 & 22.94 & 7.02 & $10-60$ & 23.71 & 7.86 & 22.36 & 6.27 & $d=.19$ \\
\hline Letter recognition & 661 & 15.56 & 3.30 & $0-20$ & 15.33 & 3.57 & 15.74 & 3.08 & $d=.13$ \\
\hline Verbal fluency & 658 & 5.29 & 2.12 & $0-13$ & 5.11 & 2.08 & 5.43 & 2.15 & $d=.15$ \\
\hline Digit span & 662 & 3.88 & .65 & $0-7$ & 3.79 & .68 & 3.96 & .61 & $d=.27 * * *$ \\
\hline Cancellation task & 565 & 13.15 & 4.09 & $1-25$ & 12.87 & 4.15 & 13.36 & 4.04 & $d=.12$ \\
\hline Figure reproduction & 548 & 4.03 & 1.97 & $0-6$ & 3.76 & 2.01 & 4.22 & 1.91 & $d=.24 * *$ \\
\hline Rhombus reproduction & 640 & .71 & .46 & $0-1$ & .70 & .46 & .71 & .45 & $w=.01$ \\
\hline
\end{tabular}

$d$. Cohen's $d ; w$. Omega from chi-square test; ES. Effect sizes; ** $p<.01 ; * * * p<.001$. 


\section{Table 3}

Regression analyses examining the associations between the family characteristics in kindergarten and achievement outcomes in Grade 9

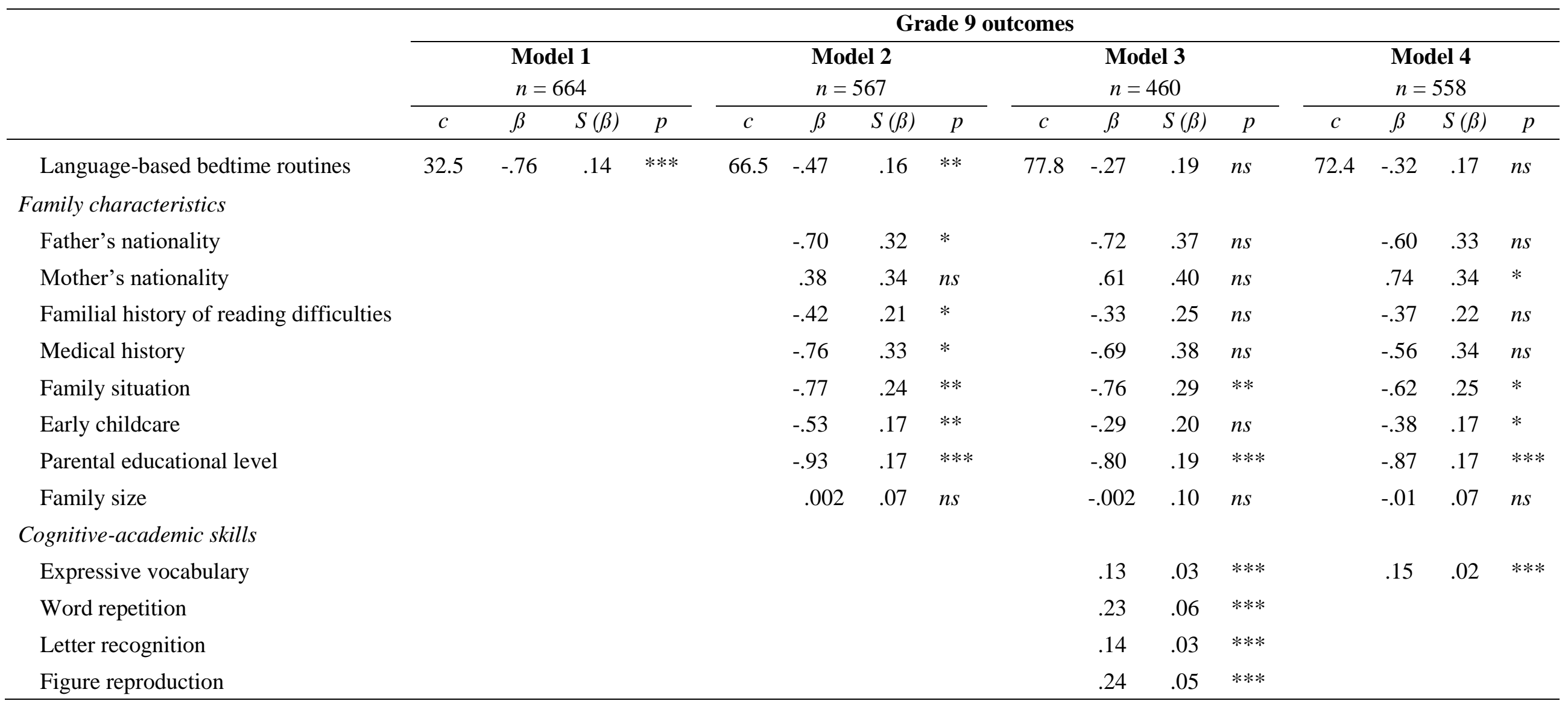

c. Percentage of concordance; $n s$. Non-significant; $* p<.05 ; * * p<.01 ; * * * p<.001$; Model 1 adjusts only for the presence of language-based bedtime routines; Model 2 controls also for all the family characteristics; Model 3 controls for all the family characteristics together with all the 16 subtests from the BSEDS battery evaluating children's cognitive-academic skills in kindergarten. For the purpose of simplicity, we opted not to present the results pertaining to the remaining 12 subtests that failed to reach statistical significance in this regression model; Model 4 controls for all the family characteristics and children's performance in the Expressive Vocabulary subtest. 
RUNNING HEAD: Bedtime routines and academic achievement

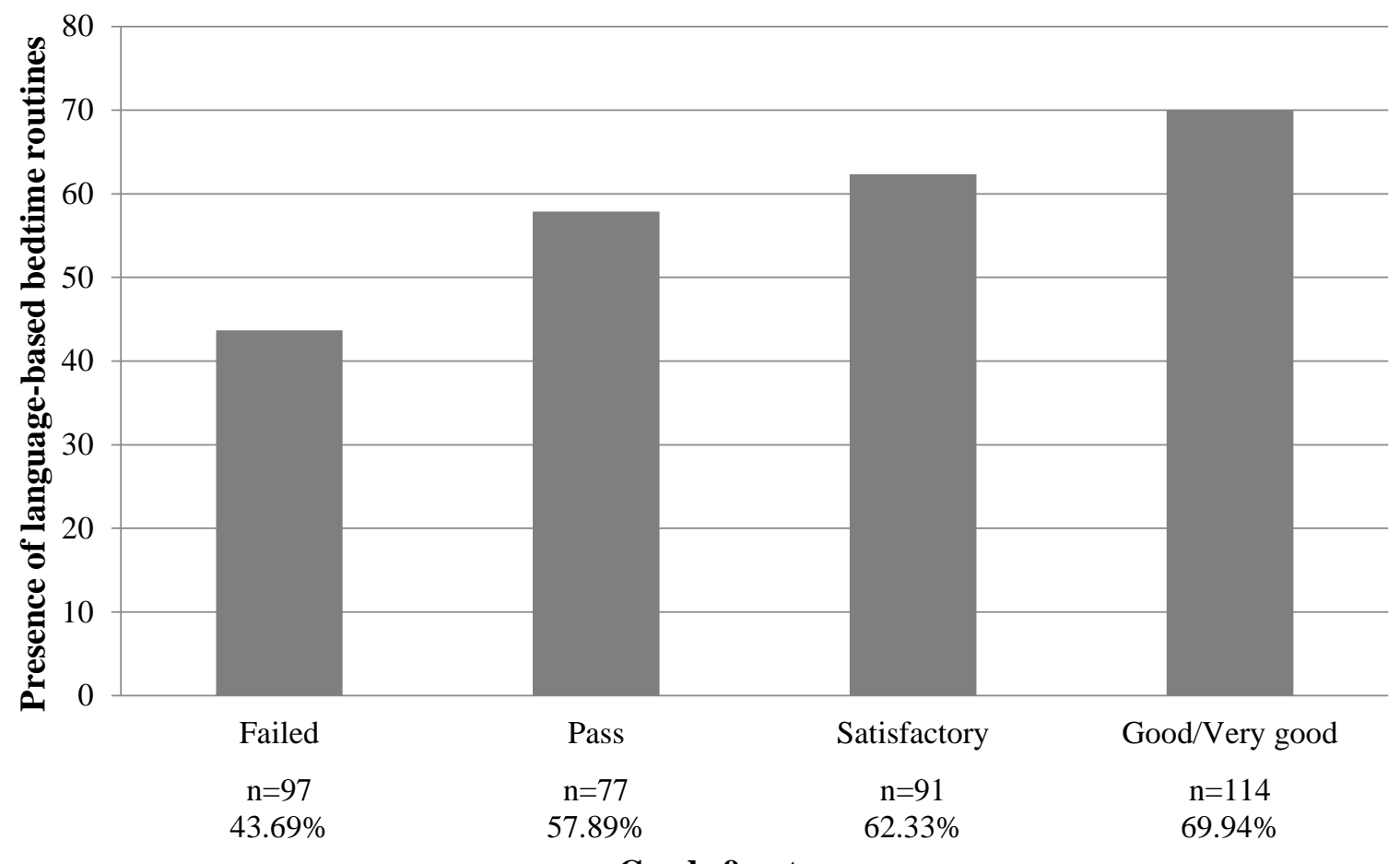

Grade 9 outcomes

\section{Figure 1}

Presence of language-based bedtime routines according to Grade 9 outcomes. 